This item was submitted to Loughborough's Research Repository by the author.

Items in Figshare are protected by copyright, with all rights reserved, unless otherwise indicated.

\title{
Internal strain analysis of CdTe thin films deposited by pulsed DC magnetron sputtering
}

PLEASE CITE THE PUBLISHED VERSION

http://dx.doi.org/10.1109/PVSC.2015.7356093

PUBLISHER

(C) IEEE

VERSION

AM (Accepted Manuscript)

\section{PUBLISHER STATEMENT}

This work is made available according to the conditions of the Creative Commons Attribution-NonCommercialNoDerivatives 4.0 International (CC BY-NC-ND 4.0) licence. Full details of this licence are available at: https://creativecommons.org/licenses/by-nc-nd/4.0/

\section{LICENCE}

CC BY-NC-ND 4.0

\section{REPOSITORY RECORD}

Kaminski, Piotr M., Ali Abbas, C. Chen, Sibel Yilmaz, Francesco Bittau, Jake W. Bowers, and Michael Walls. 2019. "Internal Strain Analysis of Cdte Thin Films Deposited by Pulsed DC Magnetron Sputtering". figshare. https://hdl.handle.net/2134/20097. 


\title{
Internal Strain Analysis of CdTe thin films Deposited by Pulsed DC Magnetron Sputtering
}

\author{
P.M. Kaminski, A. Abbas, C. Chen, S. Yilmaz, F. Bittau, J.W. Bowers, J.M. Walls \\ CREST (Centre for Renewable Energy Systems and Technology), School of Electronic, Electrical \\ and Systems Engineering, Loughborough University, Loughborough, LE11 3TU, United Kingdom
}

\begin{abstract}
Thin film CdTe was deposited by pulsed dc magnetron sputtering. Magnetron sputtering offers significant advantages for the deposition of thin film photovoltaic including low deposition temperatures and excellent coating uniformity. However the films are susceptible to stress due to the relatively high deposition energy. In this study, deposition temperature and argon gas flows have been used to minimize stress in the deposited films. TEM imaging was used to investigate the crystalline structure of the deposited films and XRD was used to measure strain. XRD analysis showed that stress can be minimized by depositing the CdTe thin film at temperatures of approximately $200^{\circ} \mathrm{C}$ using relatively high argon gas flows of $60 \mathrm{sccm}$. Moreover, this increase in substrate temperature has the further advantage of promoting larger grain sizes up to $500 \mathrm{~nm}$ in the deposited films.
\end{abstract}

Index Terms - CdTe, stress, thin film, XRD.

\section{INTRODUCTION}

Thin film CdTe solar cell technology is an important source of high volume solar modules. Significant developments have been made recently in the performance of thin film CdTe. First Solar Inc. has reported a new record cell conversion efficiency of $21.5 \%$ and module efficiencies of $17 \%$ [1], [2]. Thin film CdTe solar cells have the advantages of low manufacturing costs and high energy yields. The method used to deposit CdTe in current manufacturing is Vapour Transport Deposition (VTD). However, there are many other techniques used to deposit CdTe including electro-deposition, evaporation, close space sublimation and magnetron sputtering [3]-[5]. The advantages of magnetron sputtering include thin film uniformity, thin film density and the use of relatively low substrate temperatures. In magnetron sputtering using radio-frequency power supplies, thin films of CdTe are usually deposited at substrate temperatures of $\sim 250^{\circ} \mathrm{C}$ [6][8]. The thin films deposited by pulsed dc magnetron sputtering are susceptible to higher stress due to the relatively high energy of deposition. Substrate temperature and the working gas deposition pressure are important tools used to control stress. The stress can be source of void formation in the film and can lead to damage of the $\mathrm{CdS} / \mathrm{CdTe}$ interface during the $\mathrm{CdCl}_{2}$ recrystallization step.

\section{EXPERIMENTAL DETAILS}

Thin films of CdTe have been deposited by pulsed dc magnetron sputtering on NSG-Pilkington TEC10 glass. The glass substrates were first cleaned in 10\% IPA solution in DI water in an ultrasonic bath. This was followed by a rinse in DI water and drying. The substrates were then further cleaned and activated using a vacuum plasma treatment (500W, Ar/ $\mathrm{N}_{2}$ ambient for $5 \mathrm{~min}$ ). CdS and CdTe thin films were then sputtered on the plasma-activated TEC10 glass by pulsed DC magnetron sputtering in a "PV Solar" deposition system supplied by Power Vision Ltd., (Crewe, UK). The system is equipped with up to four $150 \mathrm{~mm}$ circular magnetrons mounted vertically around a cylindrical chamber, one of the magnetrons can be replaced with plasma source. The substrates are mounted on a vertical carrier which rotates to provide coating uniformity. The CdS/CdTe thin films were sputtered using a pulsed DC power supply (Advanced Energy Inc. Pinnacle plus 5kW) in an argon environment. The deposition temperature and Argon gas flow were controlled during the thin film CdTe deposition to investigate stress formation in the asdeposited layers.

Post annealing was also investigated as a way of reducing the stress. The films were annealed using a hot plate in air at temperatures between $300^{\circ} \mathrm{C}$ and $400^{\circ} \mathrm{C}$.

The deposited films were characterized by transmission electron microscopy (TEM), X-ray Diffraction (XRD) and by using a UV-Vis spectrophotometer. TEM of device cross-sections provided information about the grain size and crystalline structure of the deposited films. XRD was used to assess strain and stress. The stress can affect the band gap and thus the transmission edge. The spectrophotometer was used to monitor the transmission edge of the deposited films.

The XRD data was collected using a Bruker D2 PHASER. The X-ray source is $\mathrm{Cu}$ Ka with a wavelength of $1.5406 \AA$ and was set at $30 \mathrm{kV}$ and $10 \mathrm{~mA}$. The scanning mode was continuous PSD fast with a scanning range of $20^{\circ} \sim 90^{\circ}(2 \theta)$. The matched scanning step size was $0.02^{\circ}$ and the speed was $0.1 \mathrm{~s} / \mathrm{step}$. In addition, the $23.2^{\circ} \sim 24.2^{\circ}$

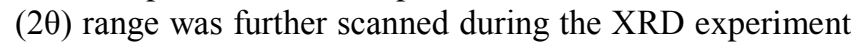
to collect more detailed data for the (111) peak analysis with a $0.01^{\circ}$ step size and 1 s/step speed.

The location of the (111) peak in the XRD spectra was monitored and used to assess the stress within the film. The bulk stress free material has the (111) peak located at $2 \Theta=23.758^{\circ}$. The strain and stress in the film can be calculated by monitoring the shift of the peak in the XRD spectra [9]. The lattice constant $d$ has been calculated using:

$$
n \lambda=2 d \sin \Theta
$$

Strain can be calculated by comparing the bulk $\mathrm{d}_{0}$ spacing with measured values d:

$$
\varepsilon=\frac{\mathrm{d}-d_{0}}{d_{0}}
$$

TEM samples of the deposited films were prepared by Focused Ion Beam (FIB) milling using a dual beam FEI Nova 600 Nanolab. A standard in situ lift out method was used to prepare cross-sectional samples through the coating into the glass substrate. A platinum over-layer was deposited to define the surface of the samples and homogenize the final thinning of the samples. TEM Images 
were obtained using a Jeol JEM 2000FX operating at 200 $\mathrm{kV}$. High resolution TEM was carried out using a FEI Tecnai F20.

The transmission of the deposited CdTe films was measured using a Varian $5000 \mathrm{UV}$-Vis spectrophotometer. The data was collected for wavelengths between $200 \mathrm{~nm}$ and $1400 \mathrm{~nm}$. Bulk CdTe has a band gap of $1.45 \mathrm{eV}$ which corresponds to an 855nm absorption edge. The absorption edge can be affected by a number of factors including film stoichiometry, grain size and stress. The transmission data has been used to calculate the band gap using the Tauc plot method [10].

\section{RESULTS}

Two sets of CdTe thin films samples were deposited, one to investigate the influence of the substrate temperature and one to investigate the influence of the Ar gas flows on the stress formation in the as deposited films. The Ar gas flow was varied in the range between $20 \mathrm{sccm}$ and $100 \mathrm{sccm}$ while the temperature was maintained constant at $250^{\circ} \mathrm{C}$. For the second set of samples, deposited for the investigation of the effect of substrate temperature, the $\mathrm{Ar}$ gas flow was fixed at $50 \mathrm{sccm}$ and the substrate temperature was varied between ambient temperatures to $400^{\circ} \mathrm{C}$. Fig. 1 shows an XRD spectrum $\left(2 \Theta=20^{\circ}-90^{\circ}\right)$ measured for the magnetron sputtered CdTe thin film. The films showed cubic phase with a (111) preferred orientation.

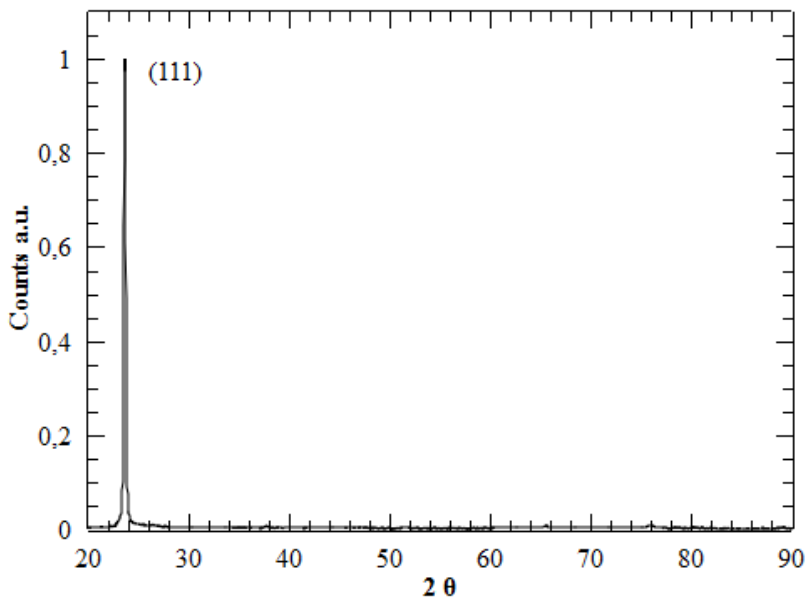

Fig. 1 XRD spectrum of an as-deposited CdTe thin film.

\section{a. Ar gas flow}

The effect of Ar gas flow was investigated in the range from $20 \mathrm{sccm}$ to $100 \mathrm{sccm}$ during depositions to evaluate the influence of the process pressure on the properties of the deposited films.

The static deposition rate of CdTe thin films was calculated from step height measurements which were obtained using a stylus profilometer. Fig. 2 shows the measured deposition rate; the deposition rate decreased with the increase of the gas flow used. A deposition rate of $2.4 \mathrm{~nm} / \mathrm{s}$ was measured for the film deposited at $20 \mathrm{sccm}$ of $\mathrm{Ar}$ and $\sim 1.7 \mathrm{~nm} / \mathrm{s}$ deposition rate was measured for films deposited at 70 and $100 \mathrm{sccm}$ Ar gas flow.

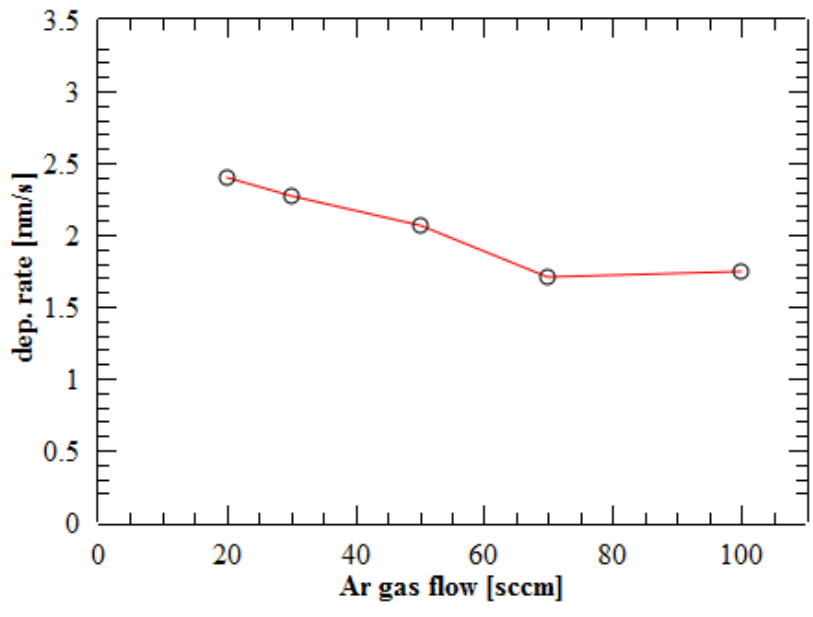

Fig. 2 Static deposition rate measured for CdTe thin films deposited at different Ar flow rate.

The TEM images of cross sections, prepared using FIB etching, were used to observe change in the film crystalline structure in response to the Ar gas flow change. Fig. 3 shows the TEM images obtained for films deposited using gas flows of $50 \mathrm{sccm}$. The films have a distinct columnar grain structure. The grains extend through the entire thickness of the film with a grain diameter of $\sim 100 \mathrm{~nm}$. The parallel line features correspond to high densities of stacking faults in the as-deposited material.

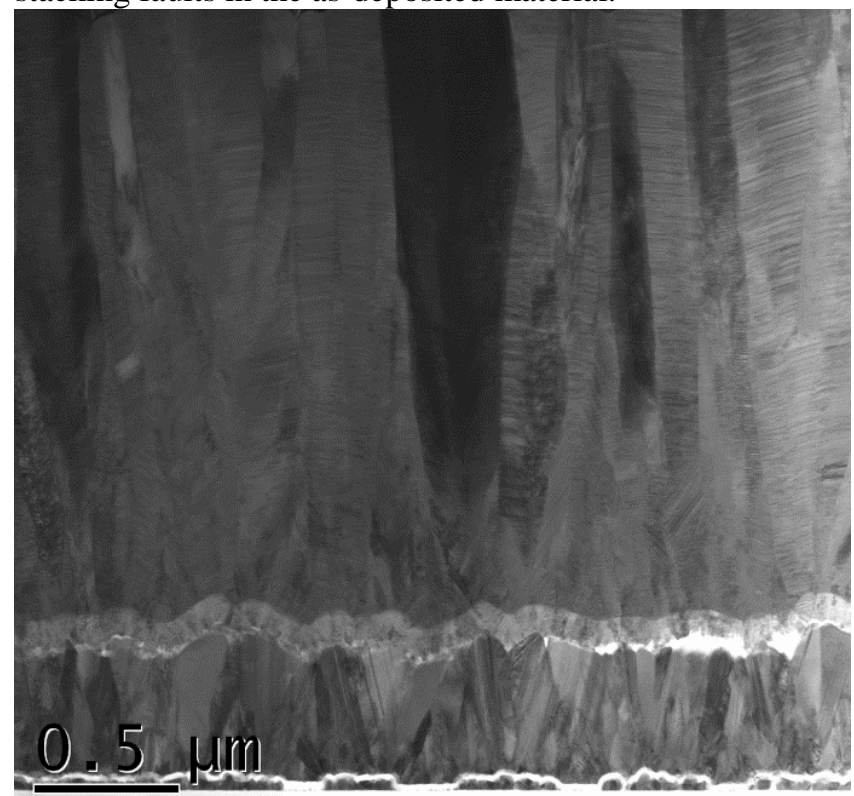

Fig. 3 TEM cross-section of CdTe films deposited using 50 sccm Ar gas flow rate.

Fig. 4 shows the TEM images obtained for films deposited at 20, 50, 70 and 100sccm Ar gas flows without substrate heating. The films deposited at low argon flow rates showed a crystalline structure consisting of small crystallites. The films deposited at higher argon flows show material with a more distinct columnar grain structure. At the higher process pressures, the grains extend through the entire thickness of the film with a grain diameter of $100 \mathrm{~nm}$ 

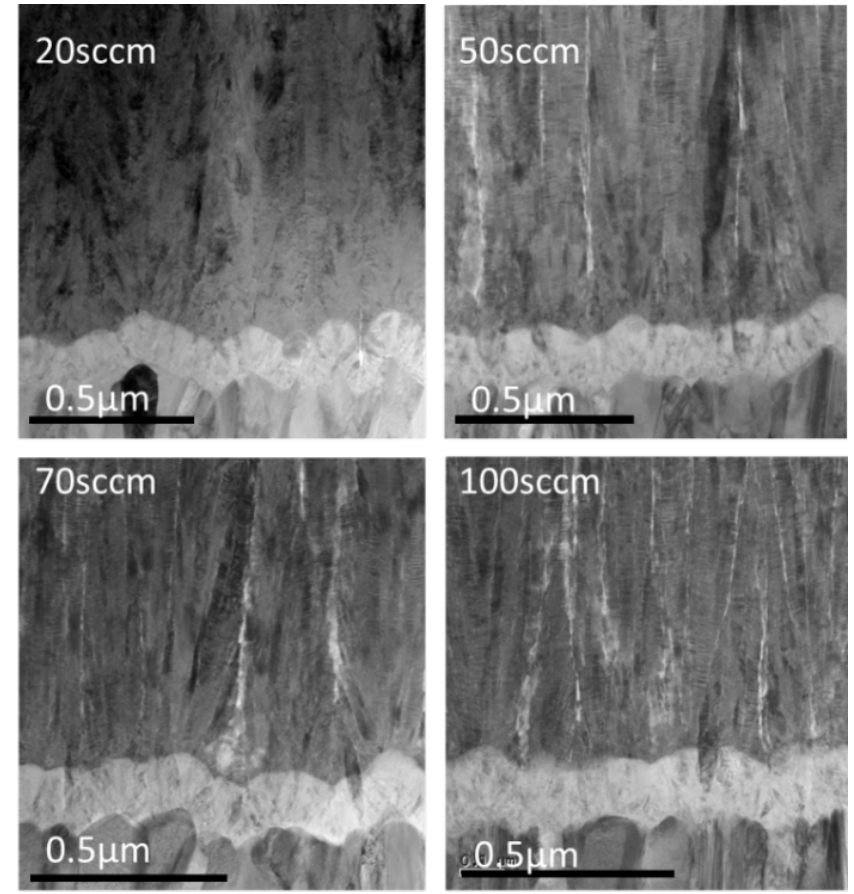

Fig. 4 TEM cross-section of CdTe films deposited using increasing Ar working gas flow rates $(20-100 s c c m)$ without substrate heating.

XRD measurements were used to observe the shift of the peak since this can be used to calculate strain in the film. The peak position for stress free bulk material is marked for reference. Fig. 4 Shows the XRD data measured for thin films deposited at different Ar gas flows. The peak shift towards lower diffraction angles indicates compressive stress formation in the deposited film.

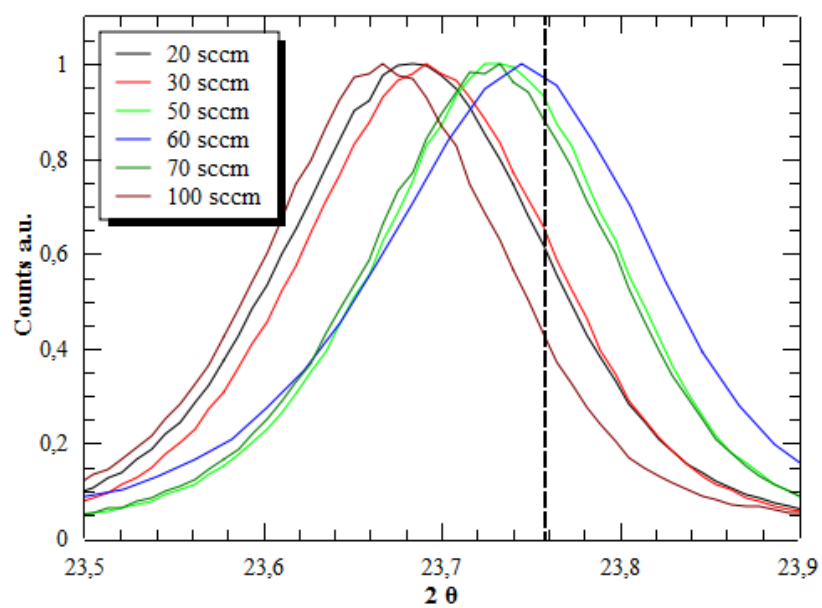

Fig. 5 XRD spectra showing (111) peak location measured for films deposited at different Ar gas flow.

The XRD data was used to calculate the $\mathrm{d}$ spacing and strain. The results of the calculations are summarized in Table 1.

Table 1 Strain of the CdTe thin films deposited at various argon flow rates.

\begin{tabular}{|l|l|l|l|l|l|l|}
\hline Ar [sccm] & 20 & 30 & 50 & 60 & 70 & 100 \\
\hline $\begin{array}{l}\text { (111) } \\
\text { location }\end{array}$ & 23.684 & 23.692 & 23.732 & 23.745 & 23.732 & 23.667 \\
\hline Strain & $3.09 \mathrm{e}-3$ & $1.06 \mathrm{e}-3$ & $1.06 \mathrm{e}-3$ & $5.45 \mathrm{e}-4$ & $1.06 \mathrm{e}-3$ & $3.77 \mathrm{e}-3$ \\
\hline
\end{tabular}

Fig. 3 shows how the strain changed as the Ar gas flow increased during the film deposition. The strain was lowest at $60 \mathrm{sccm}$ Ar gas flow.

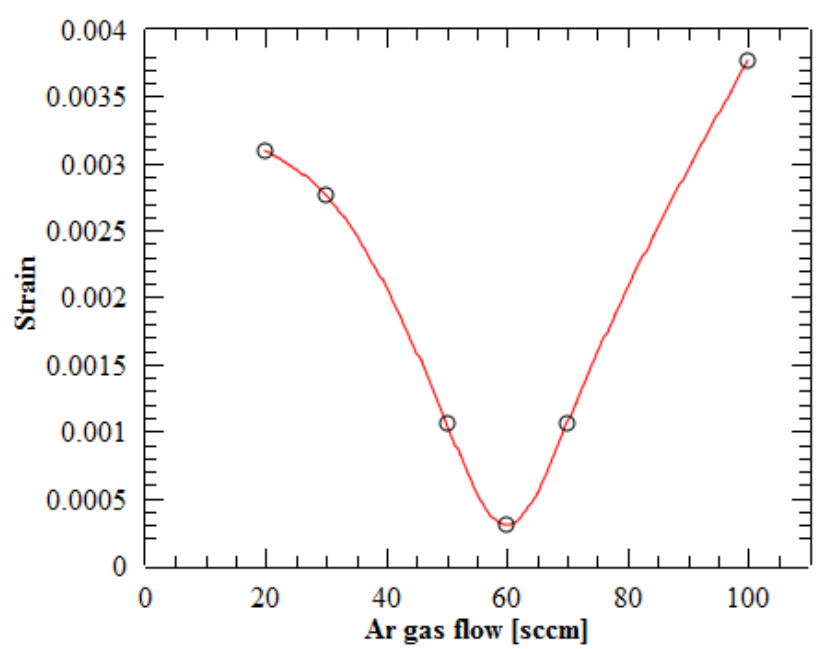

Fig. 6 Strain measured for CdTe thin films deposited at different argon flow rates. A clear minimum occurs at 60 sccm.

Fig. 6 shows the Tauc plot analysis of the CdTe films deposited at different Ar gas flow rates.

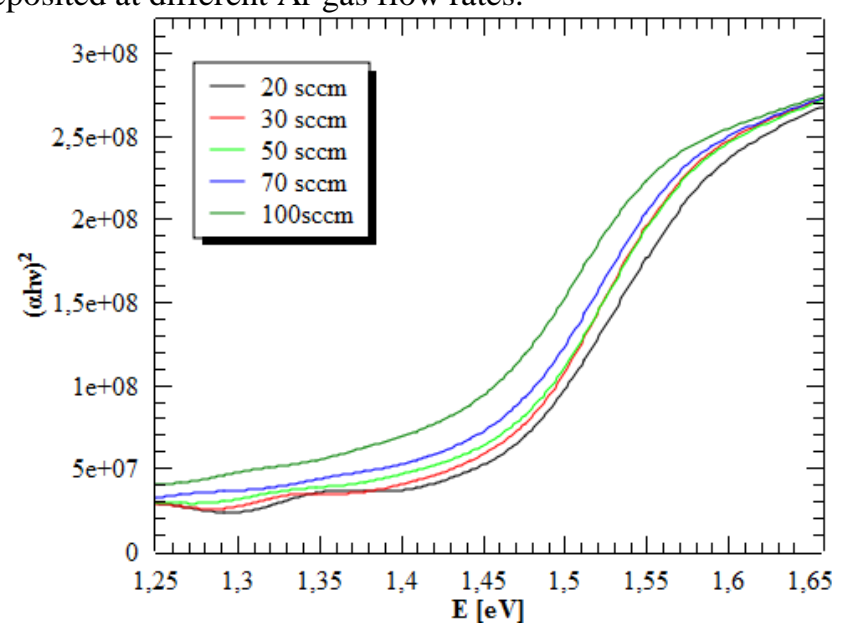

Fig. 7 Tauc plot, derived from transmission measurements for thin films deposited at different gas flows.

The band gaps calculated for thin CdTe thin films deposited at various Ar gas flow rates are plotted in Fig. 6. The analysis shows that the bandgap of the deposited films decreased as the Ar gas flow increased. In the range of conditions investigated the films deposited at 20 sccm resulted in the highest band gap of $1.425 \mathrm{eV}$.

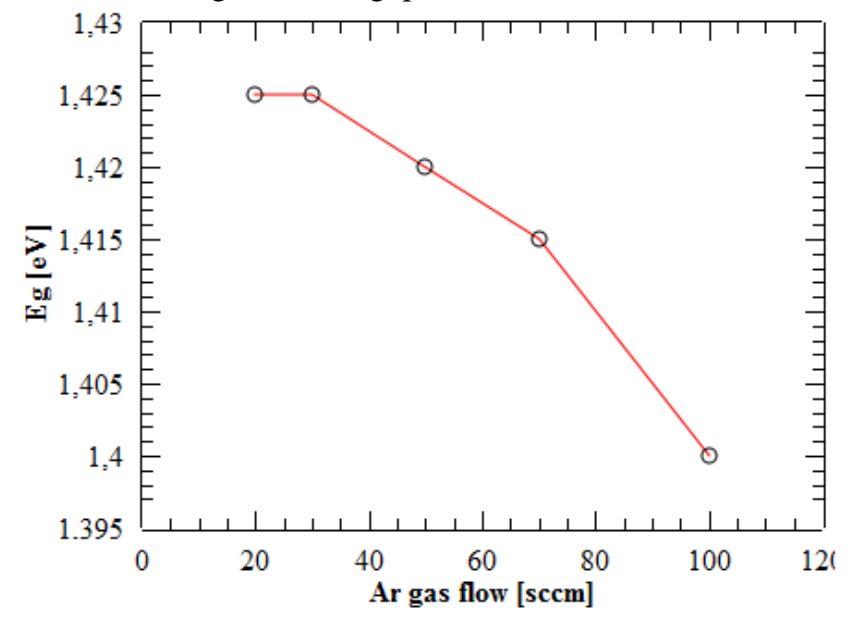

Fig. 8 The band gap of the deposited CdTe thin films as a function of the gas flow used during deposition. 


\section{b. Deposition temperature}

The influence of the substrate temperature on the films was investigated by depositing a range of films at the substrate temperatures between ambient and $400^{\circ} \mathrm{C}$. The $\mathrm{Ar}$ gas flow was fixed at 50 sccm during these experiments.

The static deposition rate of CdTe thin films deposited at different temperatures was calculated from step height measurements taken using stylus profilometer. Fig. 8 shows the measured deposition rate as function of the substrate temperature; the deposition rate decreased as the substrate temperature increased. Without additional substrate heating a deposition rate of $2.8 \mathrm{~nm} / \mathrm{s}$ was measured; the deposition rate reduced to $1.6 \mathrm{~nm} / \mathrm{s}$ when the substrate temperature was increased to $400^{\circ} \mathrm{C}$.

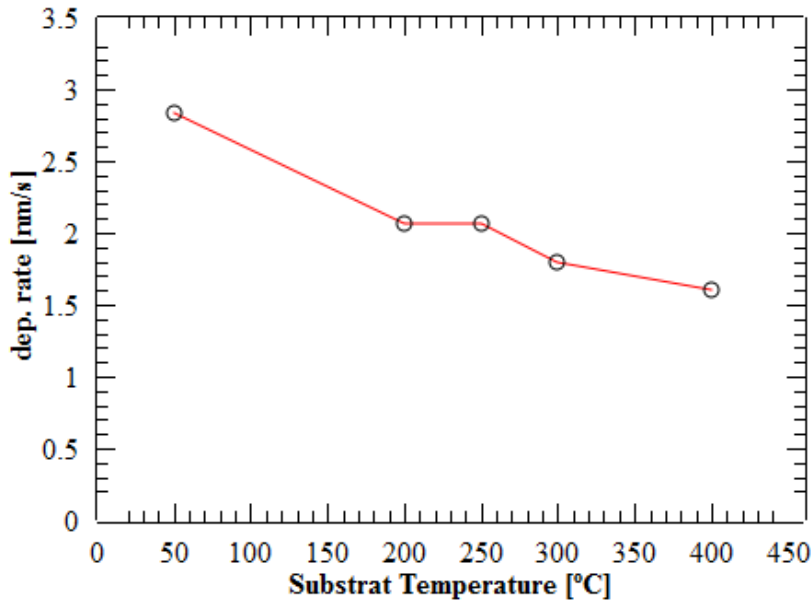

Fig. 9 Static deposition rate measured for films deposited at different substrate temperature. The data point marked at $50^{\circ} \mathrm{C}$ was deposited without substrate heating.

The TEM images of cross sections of CdTe thin films deposited at $300^{\circ} \mathrm{C}$ and $400^{\circ} \mathrm{C}$ are shown in Fig. 9. The crystalline structure of the films showed increased grain size. A grain size up to $300 \mathrm{~nm}$ was measured in the TEM cross-sections of the thin films deposited at $300^{\circ} \mathrm{C}$ and up to $500 \mathrm{~nm}$ for the thin films deposited at $400^{\circ} \mathrm{C}$.

XRD measurements were used to observe the shift of the peak to calculate the strain in the film. The peak position for stress free material is marked for reference. Fig. 10 shows the XRD data measured for thin films deposited at different substrate temperatures. For the film deposited without substrate heating the (111) peak was shifted towards lower diffraction angles indicating compressive stress in the as deposited films. The (111) peak shifted closer to the bulk material values for substrate temperatures between $200^{\circ} \mathrm{C}$ and $300^{\circ} \mathrm{C}$. For the film deposited at $400^{\circ} \mathrm{C}$ the peak shifted towards the lower angles.

The XRD data was used to calculate the $d$ spacing and strain in the deposited CdTe thin films. The results of the calculations are summarized in Table 2.

Table 2 The $d$ spacing of the CdTe thin films deposited at various substrate temperatures.

\begin{tabular}{|l|l|c|l|l|l|l|}
\hline Temp. & ambient & $100^{\circ} \mathrm{C}$ & $200^{\circ} \mathrm{C}$ & $250^{\circ} \mathrm{C}$ & $300^{\circ} \mathrm{C}$ & $400^{\circ} \mathrm{C}$ \\
\hline $\begin{array}{l}\text { (111) } \\
\text { location }\end{array}$ & 23.704 & 23.708 & 23.7652 & 23.732 & 23.732 & 2.3716 \\
\hline Strain & $2.24 \mathrm{e}-3$ & $2.08 \mathrm{e}-3$ & $2.99 \mathrm{e}-4$ & $1.06 \mathrm{e}-3$ & $1.06 \mathrm{e}-3$ & $1.74 \mathrm{e}-3$ \\
\hline
\end{tabular}
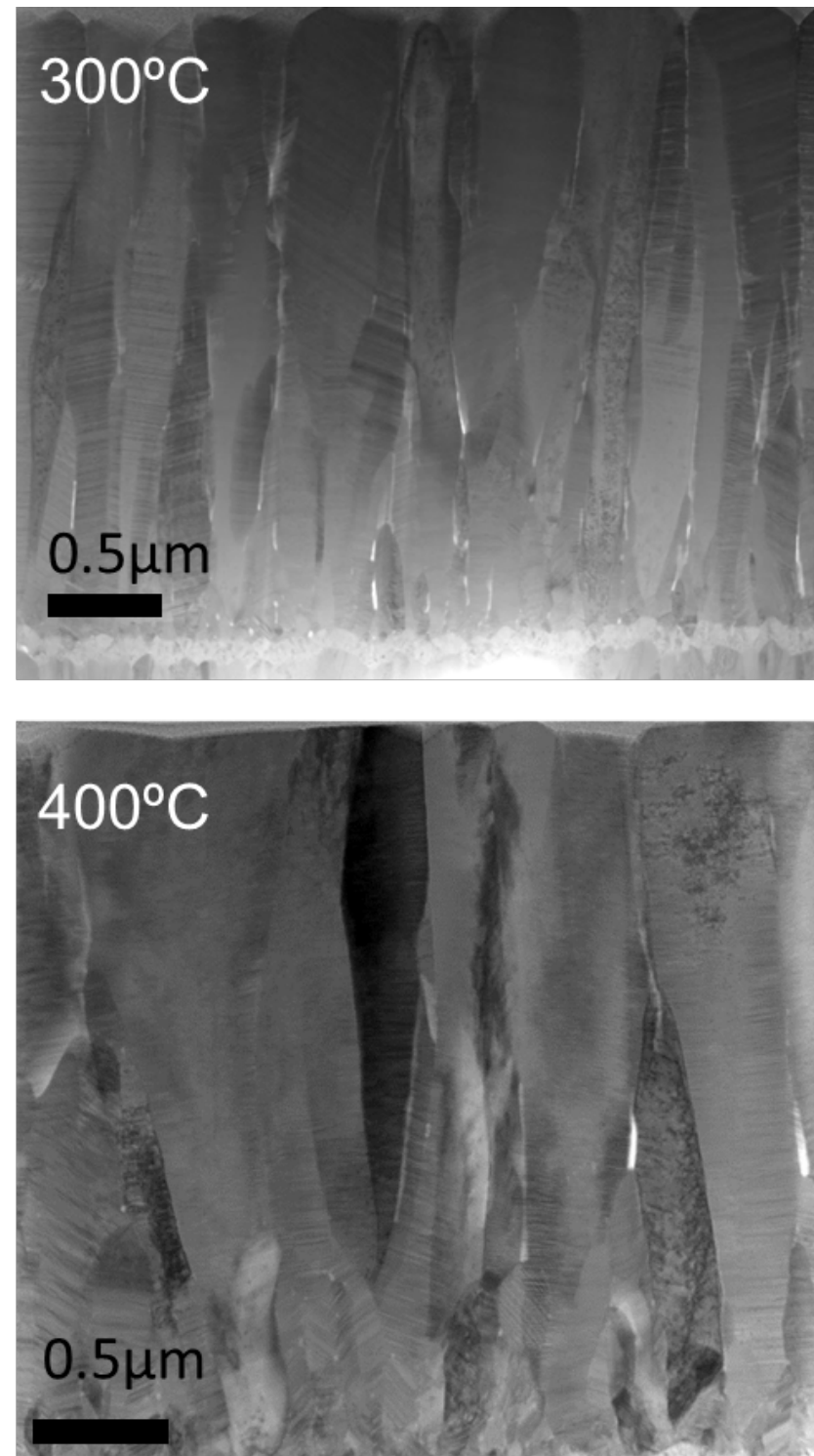

Fig. 10 TEM images of cross-section of CdTe films deposited at $300^{\circ} \mathrm{C}$ and $400^{\circ} \mathrm{C}$.

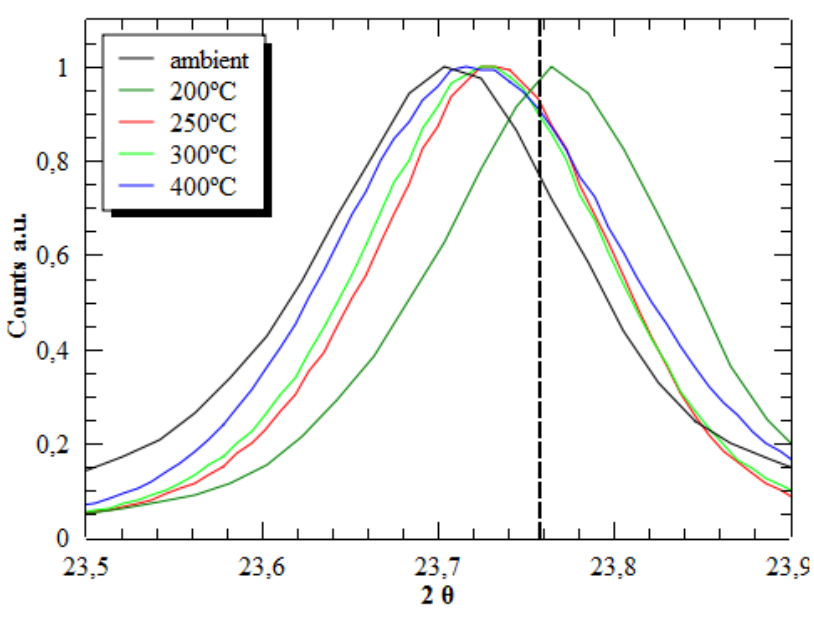

Fig. 11 XRD spectra showing the (111) peak location measured for thin films deposited at different temperatures. 


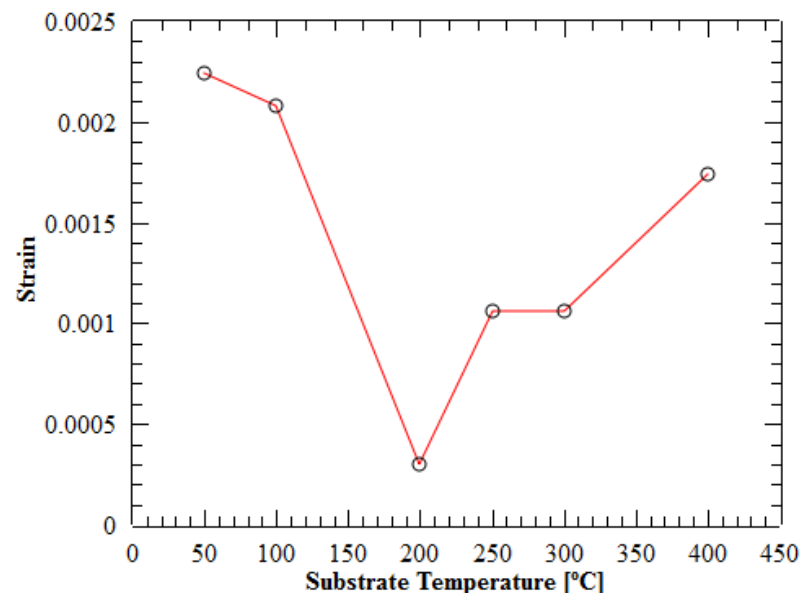

Fig. 12 The strain measured for films deposited at different substrate temperatures.

Fig. 11 shows the change in the calculated strain for the deposited films based on the measured shift of the (111) peak. The calculations show that the strain was highest for the sample deposited without additional substrate heating. The strain reduced as the temperature was increased, with minimum reached at $200^{\circ} \mathrm{C}$. For the temperature above $200^{\circ} \mathrm{C}$ the strain increased with the increase in the substrate temperature.

Fig. 12 shows Tauc plot analysis made for the CdTe thin films deposited at different substrate temperatures.

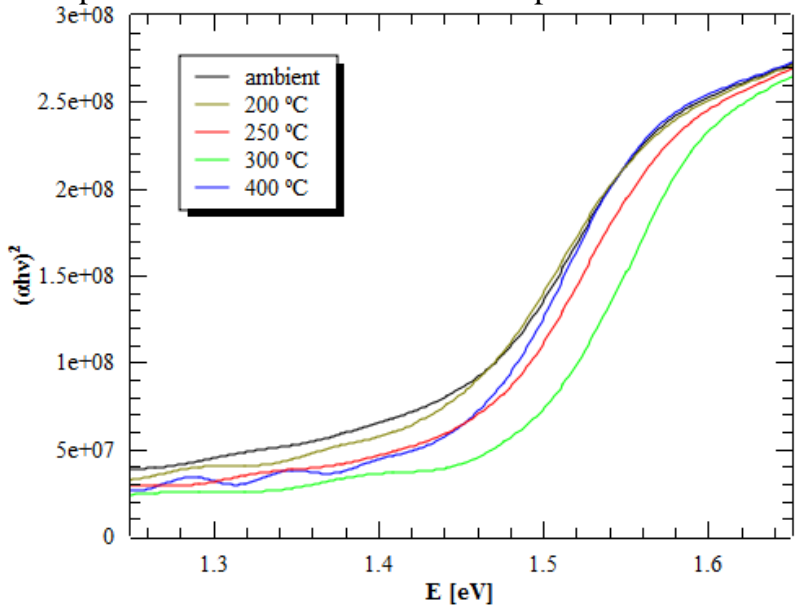

Fig. 13 A Tauc plot analysis of the CdTe thin films deposited at various substrate temperatures.

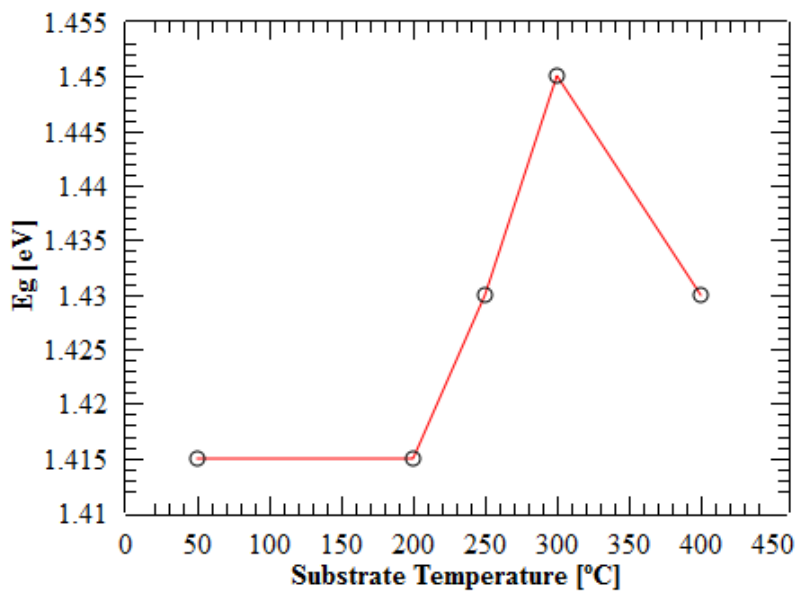

Fig. 14 The band gap of CdTe thin films as a function of substrate temperature.
The band gap values calculated from the Tauc plot for the CdTe thin films deposited at different substrate temperatures is shown in Fig. 13. The band gap approached the CdTe bulk value of $1.45 \mathrm{eV}$ for the film deposited at the substrate temperature of $300^{\circ} \mathrm{C}$.

\section{c. Sample annealing}

The deposited samples were post-annealed at $300{ }^{\circ} \mathrm{C}, 350$ ${ }^{\circ} \mathrm{C}$ and $400^{\circ} \mathrm{C}$ in an attempt to remove the stress introduced during the deposition. The films were annealed on a hot plate in air ambient for 10 minutes. Table 3 summarizes changes in the d-spacing values measured for three films investigated. The films were deposited at $100{ }^{\circ} \mathrm{C}$ and 50sccm Ar gas flow, and $300{ }^{\circ} \mathrm{C}$ and 50sccm Ar and $2 \mathrm{sccm}$ $\mathrm{O}_{2}$ gas flow and annealed at $300{ }^{\circ} \mathrm{C}, 350{ }^{\circ} \mathrm{C}$ and $400{ }^{\circ} \mathrm{C}$. Fig. 14 shows the effect of sample post annealing on the properties of the deposited films. The experiment showed that it was possible to reduce the stress by post-annealing.

Table 3 CdTe Samples Treated at Various Annealing Temperatures for 10 min.

\begin{tabular}{|c|c|c|c|c|}
\hline \multirow{2}{*}{$\begin{array}{l}\text { Samples } \\
\text { @substrate } \\
\text { temperature }\end{array}$} & \multicolumn{3}{|c|}{$\begin{array}{l}\text { d-spacing value }(\AA) \text { at various } \\
\text { annealing temperatures }\end{array}$} & \multirow{2}{*}{$\begin{array}{l}\begin{array}{l}\text { Baseline } \\
(111)\end{array} \\
\begin{array}{l}\text { Stress-free } \\
\text { state }\end{array} \\
\end{array}$} \\
\hline & $300^{\circ} \mathrm{C}$ & $350^{\circ} \mathrm{C}$ & $400^{\circ} \mathrm{C}$ & \\
\hline 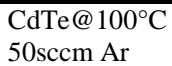 & 3.7625 & 3.7435 & 3.7403 & 3.742 \\
\hline
\end{tabular}

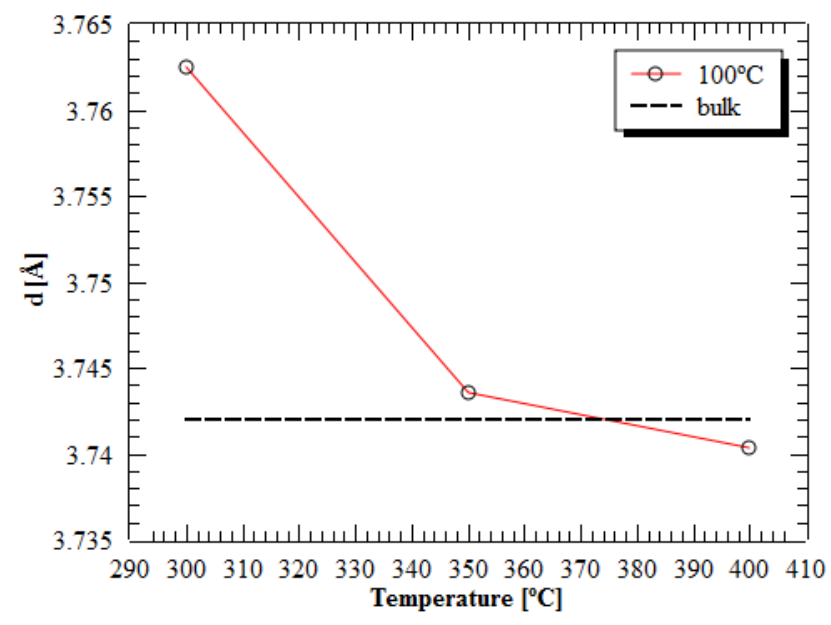

Fig. 15 The variation of d-spacing at increasing substrate temperatures

\section{CONCLUSIONS}

The influence of the argon gas flow and process pressure used and substrate temperature on the stress formation in CdTe thin films deposited by pulsed dc magnetron sputtering has been investigated. The position of the (111) peak has been measured in the XRD spectra for a variety of process conditions. Spectroscopic transmission measurements were used for Tauc plot analysis and band gap calculations. The TEM images of device cross-sections were used to analyze the crystalline structure of the as deposited materials.

When the Ar gas flow was varied during the deposition the deposition rate decreased with increase in Ar gas flow. The highest deposition rate of $2.4 \mathrm{~nm} / \mathrm{s}$ was measured for thin films deposited using a $20 \mathrm{sccm}$ Ar flow and reduced to $1.7 \mathrm{~nm} / \mathrm{s}$ measured at $100 \mathrm{sccm}$ (all films deposited at $250{ }^{\circ} \mathrm{C}$ ). The TEM cross-sectional analysis showed that the films deposited at $50 \mathrm{sccm}$ Ar gas flow have a crystalline 
structure consisting of columnar grains. The grains extend through the thickness of the deposited films. The TEM cross-sectional analysis of films deposited without substrate heating showed that the films deposited at $20 \mathrm{sccm}$ Ar gas flow have a crystalline structure consisting of small crystallites. As the gas flow was increased the thin films formed a more distinct columnar grain structure. The grains extend through the thickness of the deposited films.

The XRD measurements showed that the (111) peak position was closest to the stress free bulk values for the CdTe thin films deposited using an Ar gas flow of $60 \mathrm{sccm}$. The highest value of band gap (1.425) was produced for the thin film deposited at $20 \mathrm{sccm}$ Ar gas flow. The band gap decreased linearly with increasing Ar gas flow.

The deposition rate decreased with increasing substrate temperature during the growth of the CdTe thin films. The highest rate was $2.8 \mathrm{~nm} / \mathrm{s}$ measured for the thin films deposited without the use of substrate heating. The deposition rate decreased to $1.6 \mathrm{~nm} / \mathrm{s}$ for films deposited at $400{ }^{\circ} \mathrm{C}$ (all the films were deposited at $50 \mathrm{sccm}$ Ar flow). The cross-sectional TEM analysis showed that the substrate temperature has a significant effect on the crystalline structure of the deposited films. The grain size increased to $\sim 500 \mathrm{~nm}$ in diameter for depositions carried out at the substrate temperature of $400{ }^{\circ} \mathrm{C}$. The XRD measurements showed that the (111) peak position was closest to the bulk value for the CdTe thin films deposited between $200{ }^{\circ} \mathrm{C}$ and $300{ }^{\circ} \mathrm{C}$. The band gap of the deposited films approached bulk values of $1.45 \mathrm{eV}$ for the films deposited at $300{ }^{\circ} \mathrm{C}$.

It was possible to remove the stress from the deposited films by annealing on a hot plate. A 10 minute annealing $\mathrm{t}$ $350^{\circ} \mathrm{C}$ on a hot plate was sufficient to remove the stress from the deposited films.

The experiments have shown that the stress introduced during deposition in magnetron sputtered CdTe thin films can be controlled by manipulating working gas pressure and the temperature of the substrate. Films deposited at $200^{\circ} \mathrm{C}$ and $\mathrm{Ar}$ gas flows of $50 \mathrm{sccm}$ revealed the smallest strain. However, even at this optimized value, the $\mathrm{d}$ spacing was still higher than the $\mathrm{d}$ spacing of stress-free bulk material.

\section{REFERENCES}

[1] "First solar sets thin-film module efficiency world record of 17.0 percent." [Online]. Available: http://investor.firstsolar.com/releasedetail.cfm?Rele aseID=833971.

[2] "FIRST SOLAR ACHIEVES EFFICIENCY, DURABILITY MILESTONES,” 2015. [Online]. Available: http://investor.firstsolar.com/releasedetail.cfm?Rele aseID=895118. [Accessed: 29-May-2015].

[3] J. P. Enríquez and X. Mathew, "XRD study of the grain growth in CdTe films annealed at different temperatures,” Sol. Energy Mater. Sol. Cells, vol. 81, pp. 363-369, 2004.
[4] W. Sampath, S. Kohli, R. A. Enzenorth, K. Barth, V. Manivannan, J. Hilfiker, P. R. McCurdy, K. Barricklow, and P. Noronha, "Advances in continuous, in-line processing of stable CdS/CdTe devices," in proceedings of IEEE 33rd PVSC, 2008, pp. 1-4.

[5] A. Gupta and A. D. Compaan, “All-sputtered 14\% CdS/CdTe thin-film solar cell with ZnO:Al transparent conducting oxide,” Appl. Phys. Lett., vol. 85, no. 4, p. 684, 2004.

[6] N. R. Paudel, K. A. Wieland, and a. D. Compaan, "Ultrathin CdS/CdTe solar cells by sputtering," Sol. Energy Mater. Sol. Cells, vol. 105, pp. 109-112, Oct. 2012.

[7] R. E. Treharne, A. Seymour-Pierce, K. Durose, K. Hutchings, S. Roncallo, and D. Lane, “Optical Design and Fabrication of Fully Sputtered CdTe/CdS Solar Cells,” J. Phys. Conf. Ser., vol. 286, p. 012038, Mar. 2011.

[8] A. D. Compaan, A. Gupta, S. Lee, S. Wang, and J. Drayton, "High efficiency, magnetron sputtered CdS/CdTe solar cells,” Sol. Energy, vol. 77, no. 6, pp. 815-822, Dec. 2004.

[9] M. Fitzpatrick, A. Fry, P. Holdway, F. Kandil, J. Shackleton, and L. Suominen, "Determination of Residual Stresses by X-ray Diffraction - Issue 2,” Meas. Good Pract. Guid., no. 52, p. 74, 2005.

[10] A. Rakhshani, "Study of Urbach tail, bandgap energy and grain-boundary characteristics in CdS by modulated photocurrent spectroscopy,” J. Phys. Condens. Matter, vol. 12, pp. 4391-4400, 2000. 